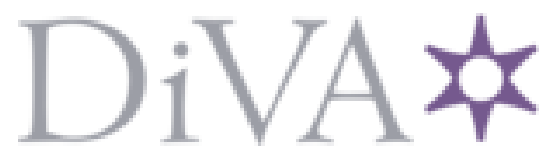

http://www.diva-portal.org

This is the published version of a paper published in Energy and Buildings.

Citation for the original published paper (version of record):

Gustafsson, M., Dermentzis, G., Myhren, J A., Bales, C., Ochs, F. et al. (2014)

Energy performance comparison of three innovative HVAC systems for renovation through dynamic simulation.

Energy and Buildings, 82: 512-519

http://dx.doi.org/10.1016/j.enbuild.2014.07.059

Access to the published version may require subscription.

N.B. When citing this work, cite the original published paper.

Permanent link to this version:

http://urn.kb.se/resolve?urn=urn:nbn:se:du-15163 


\title{
Energy performance comparison of three innovative HVAC systems for renovation through dynamic simulation
}

\author{
Marcus Gustafsson ${ }^{\mathrm{a}, \mathrm{d}, *}$, Georgios Dermentzis ${ }^{\mathrm{b}}$, Jonn Are Myhren ${ }^{\mathrm{c}}$, Chris Bales ${ }^{\mathrm{a}}$, \\ Fabian Ochs ${ }^{\mathrm{b}}$, Sture Holmberg ${ }^{\mathrm{d}}$, Wolfgang Feist ${ }^{\mathrm{b}, \mathrm{e}}$ \\ a Energy and Environmental Technology, Building technology, Högskolan Dalarna, 79188 Falun, Sweden \\ b Unit for Energy Efficient Buildings, University of Innsbruck, Technikerstraße 13, A-6020 Innsbruck, Austria \\ ${ }^{\mathrm{c}}$ Building technology, Högskolan Dalarna, 79188 Falun, Sweden \\ d Fluid and Climate Technology, Department of Civil and Architectural Engineering, KTH Royal Institute of Technology, School of Architecture and the Built \\ Environment, Brinellvägen 23, 10044 Stockholm, Sweden \\ e Passive House Institute Rheinstr. 44/46, D-64283 Darmstadt, Germany
}

\section{A R T I C L E I N F O}

\section{Article history:}

Received 27 March 2014

Received in revised form 23 July 2014

Accepted 26 July 2014

Available online 4 August 2014

\section{Keywords:}

Energy performance

Dynamic simulation

HVAC

Micro heat pump

Heat recovery

Ventilation radiator

TRNSYS

MATLAB Simulink

Renovation

\begin{abstract}
A B S T R A C T
In this paper, dynamic simulation was used to compare the energy performance of three innovative HVAC systems: (A) mechanical ventilation with heat recovery (MVHR) and micro heat pump, (B) exhaust ventilation with exhaust air-to-water heat pump and ventilation radiators, and (C) exhaust ventilation with air-to-water heat pump and ventilation radiators, to a reference system: (D) exhaust ventilation with air-to-water heat pump and panel radiators. System A was modelled in MATLAB Simulink and systems B and $C$ in TRNSYS 17. The reference system was modelled in both tools, for comparison between the two. All systems were tested with a model of a renovated single family house for varying U-values, climates, infiltration and ventilation rates.

It was found that $A$ was the best system for lower heating demand, while for higher heating demand system B would be preferable. System C was better than the reference system, but not as good as A or B.

The difference in energy consumption of the reference system was less than $2 \mathrm{kWh} /\left(\mathrm{m}^{2} \mathrm{a}\right)$ between Simulink and TRNSYS. This could be explained by the different ways of handling solar gains, but also by the fact that the TRNSYS systems supplied slightly more than the ideal heating demand.
\end{abstract}

(C) 2014 Elsevier B.V. All rights reserved.

\section{Introduction}

About $40 \%$ of the total energy use in the EU-27 is accounted for by the building sector. Thus, the building stock plays an important part in the work towards the international goals of lower energy use [1]. Two-third of the energy used in households in the EU-15 goes to space heating [2], and the largest potential for saving energy in this sector lies in renovation and upgrading of old buildings to modern energy standards [3]. Such renovation measures include changing windows, insulating roofs and external walls and changing HVAC systems. The latter of these was the objective of this study.

Many studies have previously been conducted within the field of HVAC systems and energy use of buildings, both residential and commercial buildings. Bojić et al. [4] compared three HVAC systems for heating and cooling of an office building. Wang et al. [5] made a comparison of three HVAC systems for a hypothetical

\footnotetext{
* Corresponding author. Tel.: +46 23778563.

E-mail address: mgu@du.se (M. Gustafsson).
}

apartment building. The study included 17 climate zones with various temperature and humidity conditions, and the systems compared were a direct expansion split system, a split air-source heat pump system and a closed-loop water-source heat pump with boiler an evaporative fluid cooler.

A study carried out by Gustafsson et al. [6], treating two HVAC systems similar to systems A and B of this study, indicated that these systems may indeed be potential alternatives to other, more established, systems. The results of this and the study by Wang et al. [5] also confirm the necessity to vary the climatic conditions when comparing HVAC systems.

A complete building retrofit includes many more steps and aspects than those covered in this study. Ma et al. [7] proposes a systemic approach, going all the way from planning to post-evaluation. The present study focuses on the choice of HVAC systems after a renovation of the building envelope.

There is a wide range of tools for simulation of building energy performance. In a study by Ochs et al. [8], the simulation tools MATLAB Simulink [9] and TRNSYS 17 [10] are used to model a renovated multi-family house. According to this study, there are major 


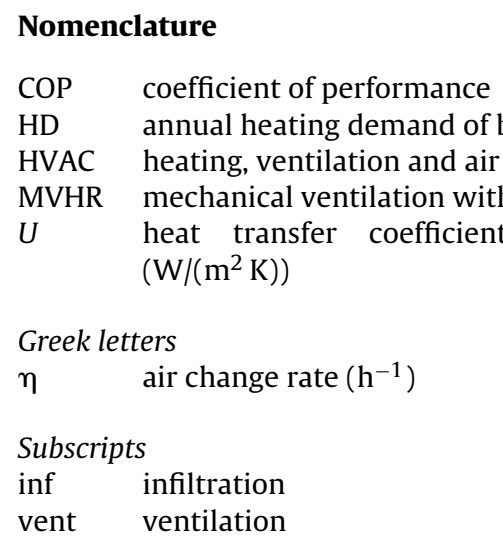

differences between the tools regarding the modelling of walls, zone nodes, windows and shading, and the time step of the solver (fixed in TRNSYS, adaptive in MATLAB Simulink). However, the study also shows good agreement in results between the two tools.

In this study, the energy performance of three innovative heating and ventilation systems was investigated through dynamic simulation and set in relation to a reference system, based on a common air-to-water heat pump. The choice of systems A, B and C was based on their potential suitability for building renovation and on the need to fill a gap in the research, while D is an established type of system, thus suitable as reference. All of the tested systems were implemented in a model of a generic single family house and tested for two renovation levels in seven different climates.

The second objective of this study was to contribute to the comparison of different simulation tools. The reference system was modelled in both MATLAB Simulink and TRNSYS 17, to enable detection of systematic differences.

\section{Methodology}

\subsection{Building model and boundary conditions}

The building modelled in this study is a semi-detached single family house, with a tempered floor area of $78 \mathrm{~m}^{2}$ and a volume of the tempered zone of $187 \mathrm{~m}^{3}$. It was defined within the FP7 project iNSPiRe [11] as a typical European single family house construction. The actual building is located in London, UK, and consists of two floors and an unheated attic, with an insulated ceiling between the top floor and the attic. In the model, the attic was excluded, and the ceiling of the top floor was taken to be the upper limit of the building envelope. Solar gains of the roof were thus disregarded and the ceiling was assumed to exchange heat directly to the ambient air. The western wall, adjacent to the neighbouring house, was taken to be adiabatic. The whole tempered area was modelled as one zone, with stairs and intermediate floor as internal walls. Simulations in TRNSYS 17 comparing the single zone model to a model with one zone per floor and one zone for the attic showed a difference in heating demand and heat load of less than $3 \%$ for the climate of London.

For open window ventilation and shading, the boundary conditions used in this study were the same as those used within [11], and to a large extent also within IEA SHC Task 44 [12]. Internal gains from occupants and electrical equipment were based on the same schedule as in [11] and [12], but since the living area for the building used in this study was only $78 \mathrm{~m}^{2}$, compared to $140 \mathrm{~m}^{2}$ in [12], the number of occupants was reduced from four to two and the gains from electrical equipment and lighting were scaled down by $50 \%$. The ventilation rate was taken to be $0.4 \mathrm{~h}^{-1}$ and the infiltration rate was calculated from a simplified model of the building envelope to be $0.1 \mathrm{~h}^{-1}$. For two of the studied climates, the influence of air change rates on the HVAC systems was tested. The infiltration rate was increased by steps of 0.1 to $0.2 \mathrm{~h}^{-1}$ and $0.3 \mathrm{~h}^{-1}$. The ventilation rate was both decreased and increased by the same amount to $0.3 \mathrm{~h}^{-1}$ to $0.5 \mathrm{~h}^{-1}$. While varying one these parameters, the other one was kept at its default value.

The desired indoor temperature, which was used to control the heating systems, was set to $20^{\circ} \mathrm{C}$. Transmission losses to the ground were modelled by setting the disturbed ground temperature as boundary temperature for the ground floor. The disturbed ground temperature was approximated as a sine, which was calculated according to standard ISO 13370 [13].

Beside ventilation and infiltration rates, the sensitivity analysis comprised climatic conditions and heating demand. Climate data for seven different European locations were used, as listed in Table 1. The chosen locations, the same as used in iNSPiRe [11], represent continental and coastal climates as well as a range of average ambient temperature and relative humidity. Data files from Meteonorm [14], based on long-term measurements, were used to generate weather data for the simulations.

For each climate, two renovation levels were defined. EnerPHit standard (HD25) [15] and Passive House standard (HD15) [16] were used to define houses with heating demands of $25 \mathrm{kWh} /\left(\mathrm{m}^{2} \mathrm{a}\right)$ and $15 \mathrm{kWh} /\left(\mathrm{m}^{2} \mathrm{a}\right)$, respectively, assuming a heat recovery efficiency of $85 \%$ and disregarding cooling demand. For the tested systems which did not include heat recovery, the actual heating demand was higher. The difference in heating demand with or without heat recovery was larger for the colder climates, where the heat recovery has a larger impact. Insulation thicknesses and related U-values were calculated using the passive house calculation tool PHPP [17]. The applied U-values for each climate and renovation level are listed in Table 1.

\subsection{Investigated systems}

All of the tested systems were set to provide space heating and ventilation, while domestic hot water use was left out of the study. The cooling demand was evaluated by measuring the number of hours with indoor temperature above $26^{\circ} \mathrm{C}$. The comparison of the systems did not include an economic analysis, and practical details on installation were not considered. Total energy consumption included heat pump compressor, auxiliary heater, pump for the space heating circuit and ventilation fans. All energy consumed was thus electricity.

The layouts of the investigated HVAC systems are described in Fig. 1.

\subsubsection{System $A$}

System A is based on a micro heat pump, in combination with mechanical ventilation with heat recovery (MVHR), with electric radiators as backup for peak heat loads. The heat pump uses the exhaust air of the heat recovery unit as source and provides heat to the supply air of the ventilation system. Thus, one compact unit can be used for combined ventilation and heating or cooling (reverse operation for cooling). Fresh outdoor air flows into the heat recovery unit, where it is heated with a recovery efficiency of up to $95 \%$. It is then further heated by the micro heat pump up to maximum $52^{\circ} \mathrm{C}$, as higher temperatures may cause odour problems, to supply space heating.

In comparison to an air source heat pump, the evaporator uses the benefit of slightly higher source side temperature and of latent heat. The evaporator extracts heat from the air using the latent heat of condensation, and the higher source side temperature improves the coefficient of performance (COP) of the heat pump. However, the air volume flow rate in the evaporator, which is equal to the flow 
Table 1

Locations for climatic data and corresponding $U$-values used in simulations.

\begin{tabular}{|c|c|c|c|c|c|c|c|c|}
\hline \multirow[t]{3}{*}{ Location } & \multicolumn{8}{|c|}{$U$-values $\left[\mathrm{W} / \mathrm{m}^{2} \mathrm{~K}\right]$} \\
\hline & \multicolumn{3}{|l|}{ HD25 } & \multicolumn{3}{|l|}{ HD15 } & \multicolumn{2}{|l|}{ Both } \\
\hline & Walls & Floor & Roof & Walls & Floor & Roof & Windows & Doors \\
\hline Stockholm & 0.126 & 0.128 & 0.126 & 0.057 & 0.057 & 0.057 & 0.90 & 0.80 \\
\hline Gdansk & 0.150 & 0.153 & 0.150 & 0.074 & 0.075 & 0.075 & 0.90 & 0.80 \\
\hline Stuttgart & 0.235 & 0.244 & 0.237 & 0.143 & 0.146 & 0.144 & 0.90 & 0.80 \\
\hline London & 0.277 & 0.290 & 0.279 & 0.175 & 0.180 & 0.176 & 0.90 & 0.80 \\
\hline Lyon & 0.320 & 0.337 & 0.323 & 0.198 & 0.204 & 0.199 & 0.90 & 0.80 \\
\hline Madrid & 0.500 & 0.544 & 0.509 & 0.361 & 0.383 & 0.365 & 0.90 & 0.80 \\
\hline Rome & 0.621 & 0.689 & 0.634 & 0.456 & 0.492 & 0.463 & 0.90 & 0.80 \\
\hline
\end{tabular}
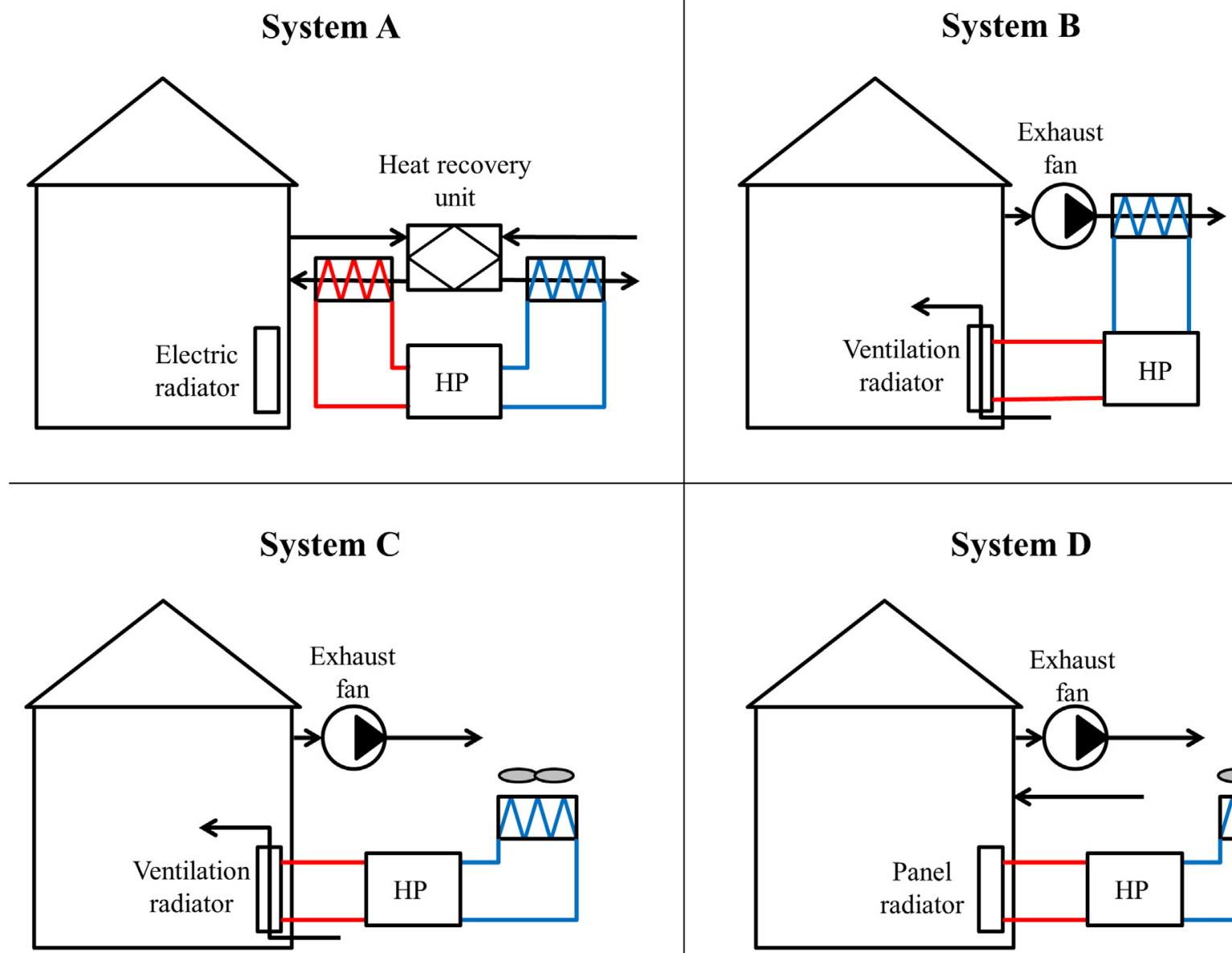

System B 
Table 2

Rated performance of micro heat pump for inlet air temperatures to the HRC unit.

\begin{tabular}{llll}
\hline & \multicolumn{4}{l}{ Air temperature $\left[{ }^{\circ} \mathrm{C}\right]$} \\
\cline { 2 - 4 } & -2 & 2 & 7 \\
\hline Heating output [kW] & 1.03 & 1.18 & 1.34 \\
COP [dimensionless] & 2.22 & 2.73 & 3.07 \\
\hline
\end{tabular}

the ventilation radiators into the building. The heat pump extracts heat from the air and delivers heated water to the radiators. The number of ventilation radiators was chosen based on the desired ventilation rate and the ideal air flow and pressure drop for one ventilation radiator [21]. The radiators were then sized to cover the heat load of the building at a distribution and return temperatures of $35 / 30^{\circ} \mathrm{C}$. The heat pump model was based on performance data for an existing air-to-water heat pump for exhaust air, as presented in Table 3 [22]. The same heating capacity, plus an auxiliary heater of $1.5 \mathrm{~kW}$, was used for all locations and renovation levels. The water flow rate was held constant at the nominal level according to test standards [23].

In the ventilation radiators, outdoor air flows in through a duct in the wall and is heated by the radiator panels before entering the room. The heat output of a radiator, either of traditional or ventilation type is proportional to the mean temperature difference between the radiator surface and the air in contact with the heated radiator surfaces. Because of the lower surrounding air temperature of a ventilation radiator compared to a traditional radiator, it can work with a lower supply water temperature. The direct contact with outdoor air gives the system the quality of fast thermal response, as the heat output is automatically adjusted with any change of ambient air temperature. Ventilation radiators have also been proven to perform well in terms of thermal comfort, giving a stable and uniform indoor climate [24], and the low water temperature is beneficial for the performance of the heat pump. From a renovation perspective, ventilation radiators in combination with mechanical exhaust ventilation can be a competitive solution, given that there is already a water heating system in the house.

\subsubsection{System $C$}

System $C$ has the same configuration as system $B$, but with a regular air-to-water heat pump without heat recovery from exhaust air. The heat pump model was based on manufacturer performance data for an existing air-to-water heat pump, as presented in Table 4 ,
Table 5

Nominal capacity and flow rate of scaled down air-to-water heat pump.

\begin{tabular}{lcccc}
\hline & \multicolumn{2}{l}{ HP capacity $[\mathrm{kW}]$} & \multicolumn{2}{c}{ HP water flow rate $[\mathrm{kg} / \mathrm{s}]$} \\
\hline Location & HD25 & HD15 & HD25 & HD15 \\
Stockholm & 1.90 & 1.70 & 0.121 & 0.108 \\
Gdansk & 1.70 & 1.50 & 0.108 & 0.095 \\
Stuttgart & 1.90 & 1.60 & 0.121 & 0.102 \\
London & 1.60 & 1.40 & 0.102 & 0.089 \\
Lyon & 1.70 & 1.40 & 0.108 & 0.089 \\
Madrid & 1.90 & 1.60 & 0.121 & 0.102 \\
Rome & 1.70 & 1.40 & 0.108 & 0.089 \\
\hline
\end{tabular}

with a nominal capacity of $3 \mathrm{~kW}$ and a nominal COP of 3.27 at A2/W35 [25].

Assuming the COP to be independent of size, the nominal heating capacity was scaled down to cover the average heat load over $24 \mathrm{~h}$ during the whole year. The nominal water flow rate, as given by test standards [23], was scaled accordingly, to allow using the same performance data. An auxiliary heater of $1 \mathrm{~kW}$ was employed when necessary. In Table 5, the nominal capacity and flow rate for each location and renovation level are listed.

For the sensitivity analysis on ventilation and infiltration, the heat pump was sized to fit the new loads, as shown in Table 6.

\subsubsection{System $D$}

The heat pump of the reference system $D$ is the same as the one used in system $C$, and was sized the same way. The traditional panel radiators were assumed to be in place before the renovation and sized to cover the heat load of the building without the extra insulation applied for HD25 or HD15. Design distribution and return temperatures were taken to be $90 / 70^{\circ} \mathrm{C}$, but in the renovated houses studied, the actual radiator water temperatures would be lower, due to the lower heat load.

\subsection{Simulation tools}

System A was modelled in MATLAB Simulink and systems B and C were modelled in TRNSYS 17, while the reference system D was modelled in both tools, to enable comparison between this and the other systems while reducing the risk of systematic errors. This also allowed for a comparison between the two simulation tools. A time step of five minutes was used in the TRNSYS simulations, while MATLAB Simulink uses an adaptive time step.

Table 3

Rated performance of the exhaust air-to-water heat pump of system B.

\begin{tabular}{|c|c|c|c|c|c|c|}
\hline & \multirow[t]{2}{*}{ Water temperature $\left[{ }^{\circ} \mathrm{C}\right]$} & \multicolumn{5}{|c|}{ Air flow rate [1/s] } \\
\hline & & 30 & 40 & 50 & 60 & 70 \\
\hline Heating output & 35 & 1.14 & 1.30 & 1.42 & 1.46 & 1.50 \\
\hline$[\mathrm{kW}]$ & 45 & 1.15 & 1.24 & 1.30 & 1.35 & 1.37 \\
\hline \multirow[t]{2}{*}{ COP [dimensionless] } & 35 & 4.46 & 4.76 & 5.12 & 5.24 & 5.43 \\
\hline & 45 & 3.34 & 3.49 & 3.72 & 3.86 & 3.91 \\
\hline
\end{tabular}

Table 4

Rated performance of the air-to-water heat pump of systems C and D.

\begin{tabular}{|c|c|c|c|c|c|c|c|c|c|}
\hline & \multirow[t]{2}{*}{ Water temperature $\left[{ }^{\circ} \mathrm{C}\right]$} & \multicolumn{8}{|c|}{ Air temperature $\left[{ }^{\circ} \mathrm{C}\right]$} \\
\hline & & -15 & -7 & 2 & 7 & 10 & 12 & 20 & 30 \\
\hline Heating output & 35 & 1.70 & 2.60 & $3.00^{*}$ & 4.50 & 4.60 & 4.80 & 5.00 & 5.50 \\
\hline \multirow[t]{2}{*}[\mathrm{kW}]{} & 45 & 1.50 & 2.30 & 2.80 & 4.00 & 4.20 & 4.40 & 4.60 & 5.00 \\
\hline & 55 & 1.30 & 2.00 & 2.70 & 3.70 & 3.80 & 4.00 & 4.30 & 4.70 \\
\hline $\mathrm{COP}$ & 35 & 1.90 & 2.85 & $3.27^{* *}$ & 4.64 & 4.83 & 5.00 & 5.27 & 5.70 \\
\hline \multirow[t]{2}{*}{ [dimensionless] } & 45 & 1.60 & 2.20 & 2.65 & 3.55 & 3.67 & 3.75 & 4.04 & 4.41 \\
\hline & 55 & 1.16 & 1.70 & 2.12 & 2.74 & 2.87 & 3.10 & 3.30 & 3.45 \\
\hline
\end{tabular}

\footnotetext{
${ }^{*}$ Nominal heating output
}

** Nominal COP. 
Table 6

Nominal capacity and water flow rate of heat pump for varying ventilation and infiltration rates.

\begin{tabular}{|c|c|c|c|c|c|}
\hline \multirow[t]{2}{*}{ Location } & \multirow[t]{2}{*}{ Parametric variation } & \multicolumn{2}{|c|}{ HP capacity [kW] } & \multicolumn{2}{|c|}{ HP water flow rate $[\mathrm{kg} / \mathrm{s}]$} \\
\hline & & HD25 & HD15 & HD25 & HD15 \\
\hline \multirow[t]{4}{*}{ Stockholm } & $\eta_{\text {vent }}=0.3$ & 1.70 & 1.40 & 0.108 & 0.089 \\
\hline & $\eta_{\text {vent }}=0.5$ & 2.20 & 1.90 & 0.140 & 0.121 \\
\hline & $\eta_{\mathrm{inf}}=0.2$ & 2.20 & 1.90 & 0.140 & 0.121 \\
\hline & $\eta_{\mathrm{inf}}=0.3$ & 2.40 & 2.10 & 0.153 & 0.134 \\
\hline \multirow[t]{4}{*}{ Rome } & $\eta_{\text {vent }}=0.3$ & 1.60 & 1.30 & 0.102 & 0.083 \\
\hline & $\eta_{\text {vent }}=0.5$ & 1.80 & 1.50 & 0.115 & 0.095 \\
\hline & $\eta_{\text {inf }}=0.2$ & 1.80 & 1.50 & 0.115 & 0.095 \\
\hline & $\eta_{\text {inf }}=0.3$ & 1.90 & 1.60 & 0.121 & 0.102 \\
\hline
\end{tabular}

In MATLAB Simulink the complex building model of the Carnot Blockset was used. The heat pump model in system D was based on performance map data. The heating capacity was approximated linearly depending on the source inlet air temperature and the sink outlet water temperature. The COP was based on Carnot COP and the Carnot performance factor. In the initialization of the model (pre-processing) the Carnot performance factor and the linear coefficients for the heating capacity were calculated in order to achieve the best possible agreement.

In TRNSYS, the heat pump was modelled using a performance map with data on heating capacity and compressor power for a range of testing points. The heat output and COP of the heat pump were calculated in the model through interpolation between these points.

The ventilation radiator model of systems $B$ and $C$ was based on an Excel model provided by a radiator manufacturer, which in turn was based on measurements on their own products [26]. A link embedded in TRNSYS was used to connect the Excel model to the rest of the system.

\subsection{Controls}

All heating systems and auxiliary heaters were controlled by on/off differential controllers with hysteresis. The governing temperature was the indoor air temperature. The set point for the primary heating systems was $20^{\circ} \mathrm{C}$, with upper and lower dead bands of $0.25 \mathrm{~K}$. Similarly, the auxiliary heaters had a set point of $19.75^{\circ} \mathrm{C}$ and allowed the temperature to vary between $19.5^{\circ} \mathrm{C}$ and $20^{\circ} \mathrm{C}$. The set point for the auxiliary heater was set to a lower value to avoid operation during hours when the primary system could manage the heating. The ventilation was running independently of the heating control signals, but in systems A and B the heat pumps were bypassed when no heating was needed.

\section{Results}

Fig. 2 shows the annual heating supply by heat pump and compressor of the reference system and Fig. 3 the electrical energy consumption of the reference system, comparing MATLAB Simulink and TRNSYS for all locations and renovation levels. In Fig. 2, the solid and dashed lines mark the heating demand with heat recovery for the HD25 and the HD15 houses, respectively. The difference between the two tools exceeded $5 \%$ only for Madrid and Rome, where the difference was $7 \%$ and $6 \%$ respectively for supplied heating and $11 \%$ and $8 \%$ respectively for electrical energy consumption. The trends were similar for both energy standards of the house. In TRNSYS, all systems overshot the ideal heating demand, which was defined as the heating required to keep the indoor air temperature at or above $20^{\circ} \mathrm{C}$ at all times, by $1 \mathrm{kWh} /\left(\mathrm{m}^{2}\right.$ a) to $2 \mathrm{kWh} /\left(\mathrm{m}^{2} \mathrm{a}\right)$. In Simulink, system D followed the ideal heating demand more closely. The ideal heating demand simulated in Simulink was higher than in TRNSYS for all climates except for Madrid and Rome, where

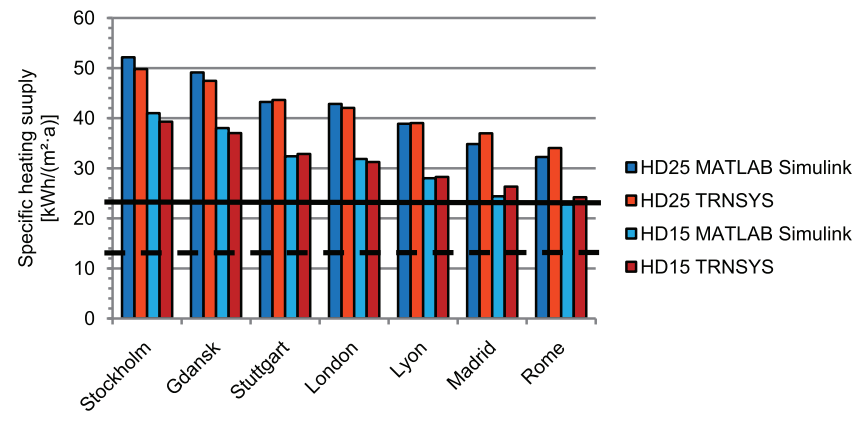

Fig. 2. Annual heating supplied by system D in MATLAB Simulink and in TRNSYS. Solid line marks heating demand of HD25 with heat recovery; dashed line marks heating demand of HD15 with heat recovery.

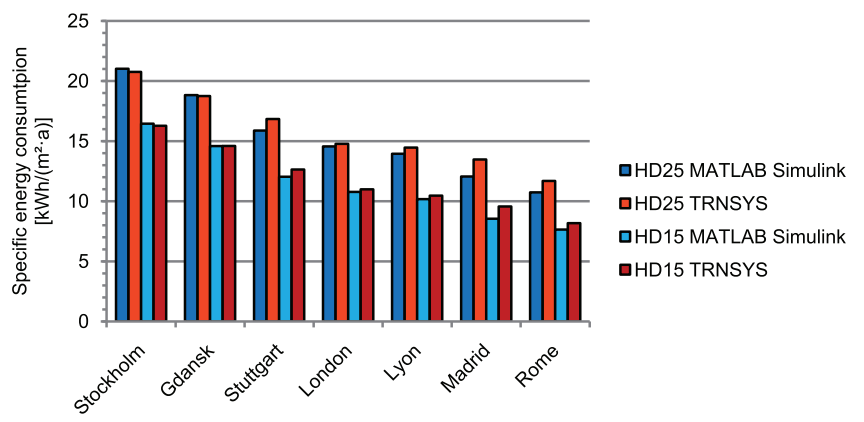

Fig. 3. Electrical energy consumption of system D in MATLAB Simulink and in TRNSYS.

it was lower. The seasonal performance factor of the heat pump was around 0.1 higher in Simulink than in TRNSYS. In terms of gains and losses of the house, some differences were noted in absorbed solar energy. The solar gains in MATLAB Simulink were around $3 \mathrm{kWh} /\left(\mathrm{m}^{2} \mathrm{a}\right)$ higher than in TRNSYS for the climates of Madrid and Rome, while for other climates the solar gains were $2.5 \mathrm{kWh} /\left(\mathrm{m}^{2} \mathrm{a}\right)$ to $5 \mathrm{kWh} /\left(\mathrm{m}^{2} \mathrm{a}\right)$ lower in MATLAB Simulink than in TRNSYS.

The relative energy consumption of systems A, B and C compared to the reference system D is shown in Fig. 4. System $A$ is set in relation to the performance of system $D$ in MATLAB Simulink, while $B$ and $C$ are set in relation to the TRNSYS model of system $D$.

System A had the lowest energy consumption for both renovation levels in all climates. The largest savings compared to system D were seen for the HD15 in cold climates, with a maximum of 36\% for the climates of Stockholm and Gdansk.

System B showed a similar trend, but with less difference between the coldest and the warmest climates, and also less difference between the two renovation levels. For the HD25 house it was close to system A in energy consumption in all climates. The maximum energy saving compared to system D was $23 \%$ for the HD15 house in Stockholm. 


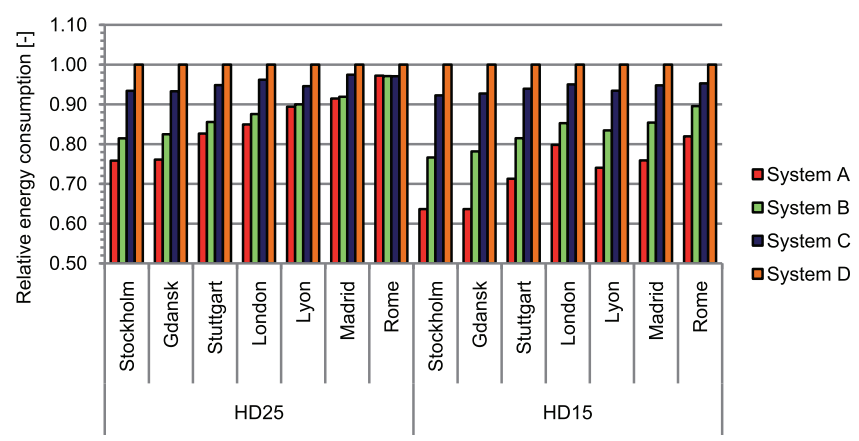

Fig. 4. Energy consumption of tested systems compared to the reference system for varying climate and heating demand.

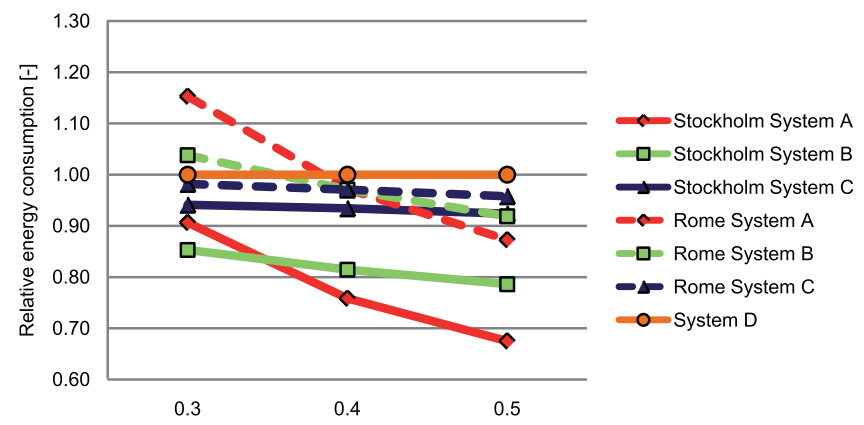

Fig. 5. Energy consumption of tested systems (HD25) compared to the reference system for varying ventilation rate.

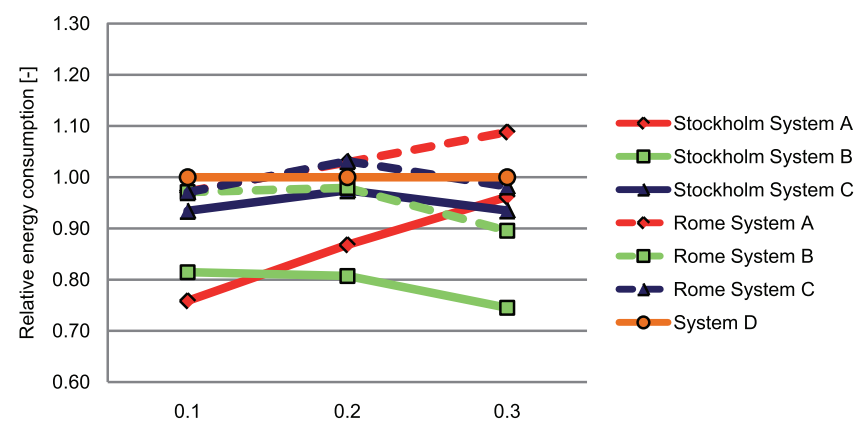

Fig. 6. Energy consumption of tested systems (HD25) compared to the reference system for varying infiltration rate.

For system C, the energy use was consistently lower than the reference, with only small variations with the climates. It was the best system, together with A and B, for the HD25 house in Rome. The energy savings compared to system D ranged from 3\% for the HD25 house in Madrid and Rome to 8\% for the HD15 house in Stockholm.

The influence of ventilation rate on the energy performance is shown in Fig. 5 and the influence of infiltration rate in Fig. 6, both for the HD25 house. System A was affected in a positive direction relative to system $D$ when the ventilation rate was increased and in a negative way when the infiltration rate was increased. With a ventilation rate of $0.5 \mathrm{~h}^{-1}$, the energy performance of system $A$ was better than the reference for the climate of Rome. For system B, both ways of increasing the air change rate were favourable compared to system D. With an infiltration rate of $0.2 \mathrm{~h}^{-1}$, system B had the best energy performance for Stockholm, and with an infiltration rate of $0.3 \mathrm{~h}^{-1}$ it was the best system also for Rome. System C was not significantly influenced in any way in relation to the reference system by either of these parameters.

Fig. 7 shows the number of hours with room temperature above $26^{\circ} \mathrm{C}$ for the reference system. In Lyon, Madrid and Rome, the room

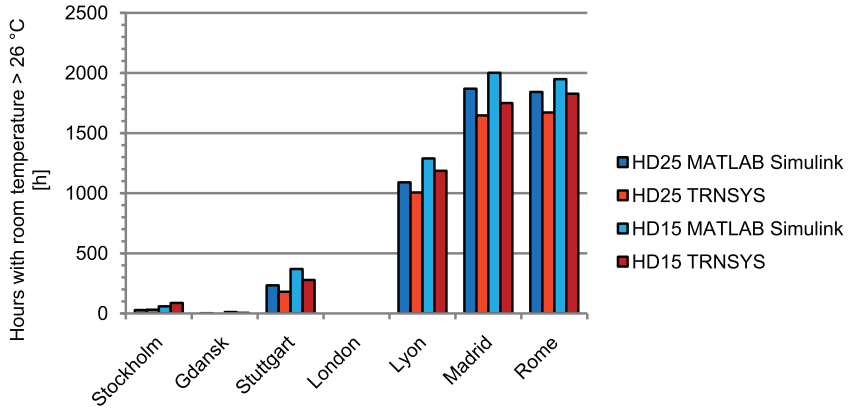

Fig. 7. Number of hours with room temperature above $26^{\circ} \mathrm{C}$ for the reference system in MATLAB Simulink and in TRNSYS.

temperature reached above $26^{\circ} \mathrm{C}$ for $1000 \mathrm{~h}$ to $2000 \mathrm{~h}$ per year, with slightly higher figures for the HD15 house. All systems met the criteria to keep the temperature above $19.5^{\circ} \mathrm{C}$ at all times.

\section{Discussion}

In the comparison between the two simulation tools, some deviations were observed for the performance of system $\mathrm{D}$. The relatively high differences in percentage for Rome and Madrid could partly be explained by the low heating demand for these locations. Also, in TRNSYS all the tested systems provided $1 \mathrm{kWh} /\left(\mathrm{m}^{2} \mathrm{a}\right)$ to $2 \mathrm{kWh} /\left(\mathrm{m}^{2} \mathrm{a}\right)$ more than the ideal heating demand, notably with a mutual difference of less than $1 \mathrm{kWh} /\left(\mathrm{m}^{2} \mathrm{a}\right)$ between them. There also seemed to be a difference in how the two tools handle solar gains of a house. This showed in the number of hours with overheating, where the simulations in MATLAB Simulink gave a higher number in most cases. It could also have influenced the difference in annual heating demand.

The house was modelled as a single zone, disregarding solar gains to the roof. For the heating demand, particularly for London and colder climates, this approach makes little or no difference to the results compared to a model including roof and attic, since the solar gains are relatively small during the heating season. In warmer climates the difference could be more significant, and if the cooling demand is to be determined all solar gains should be taken into account.

Heating systems that are based on heat recovery of ventilation air are always limited by the ventilation rate. For both systems $A$ and $B$ in this study, the relatively low ventilation rate limited the heating capacity of the respective heat pumps and increased the need for auxiliary heating. Varying the ventilation rate, it was shown that the performance of these systems system relative to the reference system improved with a higher ventilation rate, and vice versa. When it comes to varying the infiltration rate, $A$ and $B$ are affected in opposite ways. In system $B$, the exhaust fan enables the exhaust air heat pump to utilize both the ventilation and infiltration air to deliver energy to the ventilation radiators. In system A, the heat recovery unit can only make use of the ventilation part, while the infiltrated air just adds to the heat losses.

All systems were compared for the same infiltration rate. However, the infiltration rate of a house is dependent on the pressure difference between indoor and outdoor, which in turn depends on the type of ventilation system installed [27]. System A, using balanced ventilation, would have a lower infiltration rate than the other systems for the same house.

In the present study, the use of mechanical ventilation was accounted for only during the months when the house required heating. In Sweden, building regulations [28] do not allow replacing mechanical ventilation with opening windows. Extending the ventilation period would strike the hardest on system $A$, since the MVHR consumes more energy than a simple exhaust fan. For the 
HD15 house in Stockholm, applying mechanical ventilation all year would increase the total energy consumption of system A by $8 \%$, whereas the increase for systems B, C and D would be $2-3 \%$ for the same case. However, bypassing the heat recovery unit during summer would reduce the impact on energy consumption for system A.

For system C, some savings were seen due to the lower water temperature enabled by the use of ventilation radiators. However, the water temperature in the reference system was already low, since the existing radiators were sized for a higher heat load. The largest reduction in energy consumption was seen for system A, where the air heat recovery cut down the heating demand significantly compared to that of other systems. System B consumed less energy than system $C$ due to the higher source side temperature of the exhaust air heat pump.

System A was the system that benefitted the most from a higher renovation standard. It had the lowest energy consumption for both renovation level and all climates, but for the HD25 house it consumed almost as much energy as system $B$, despite the advantage of MVHR. This confirms the premise that the micro heat pump is best applied in very low energy building such as Passive Houses and suggests that a system like B would be preferable in houses with higher heating demand.

In a complete building retrofit, it may not always be feasible from the economic point of view to achieve Passive House standard. For the climates of Gdansk and Stockholm 200-300 mm of extra insulation is required to go from HD25 to HD15 level. This will of course increase the investment costs significantly, even though the total insulation thickness could be reduced by choosing better insulating windows and improve the air tightness in such cold climates. On the other hand, insulation of the floor may not always be feasible, thus increasing the need for improvements on other parts of the building envelope.

The level of insulation can also be important for the choice of heating system in terms of thermal comfort. If ventilation radiators are used in heavily insulated houses, as in systems B and C, there could be problems with cold draft when the outdoor temperature is at or near the balance temperature of the house. As the heating system will not be active above the balance temperature, a lower balance temperature will allow colder air to be supplied through the radiators.

In warmer climates, a thicker insulation leads to slightly higher indoor temperatures during summer, thus occasionally increasing the cooling demand. The observed indoor temperatures for Lyon, Madrid and Rome in this study indicate that the tested house would need a cooling device in these climates; a service which could be provided by reversing the operation of the heat pump.

A complete energy system for a house need also include domestic hot water. Air-to-water heat pumps, like the ones used in systems B, C and D, are normally designed to handle both space heating and hot water. System $A$, on the other hand, would require a complement to the air-to-air micro heat pump to be able to provide this service. In heavily insulated houses, where heat losses are minimized, the relative importance of hot water use will naturally become larger.

The heat pump used in systems $C$ and $D$ was scaled down from $3.0 \mathrm{~kW}$ to heating capacities ranging from $1.2 \mathrm{~kW}$ to $2.4 \mathrm{~kW}$, assuming that the COP remained the same. In reality, the Carnot efficiency, and thus the COP, might not be independent of the capacity of the heat pump. For a scaling down of this relatively small magnitude, it may not have a great impact, but it should be taken into consideration that it could affect the result of systems $C$ and $D$, especially for the warmer climates where the heat pump has been scaled down more.

The TRNSYS heat pump model used was not designed for variable speed. The exhaust air heat pump of system B would, in reality, be able to vary the compressor speed to cope with higher loads, and would therefore need to use less auxiliary heating than the model did. The micro heat pump of system A also has the potential to perform slightly better with a speed controlled compressor. The influence of control strategy could be a subject for future studies.

\section{Conclusions}

In dynamic simulation of building energy performance, the results are to some extent dependent on the choice of simulation tool. The differences between MATLAB Simulink and TRNSYS 17 were in this study found to be larger for warmer climates, possibly because of differences in how solar gains are treated in the two tools. Also, the TRNSYS systems supplied slightly more than the ideal heating demand. Still, the magnitudes of the deviations were acceptable.

Both systems A and B were more favourable in colder climates; system A due to the heat recovery and system $B$ due to the higher source side temperature of the heat pump. According to the results of this study, system $A$ is the best option in well-insulated houses with low infiltration and high ventilation rate. For a less insulated house with higher infiltration rate, located in the same climate, system $B$ would have the best energy performance. The performance of system $C$ shows that some energy can be saved by applying ventilation radiators instead of traditional panel radiators, although in this case the panel radiators were sized for a higher heat load and thus also enabled a low water temperature. System $C$ was better than the reference system, but not as good as A or B.

In future studies of retrofitted buildings, it is suggested to include the use of domestic hot water, as this will make up a larger part of the total energy consumption when the space heating demand is lowered through renovation of the building envelope. In warm climates, cooling demand should also be considered.

\section{Acknowledgement}

The research leading to these results has received funding from the European Union's Seventh Programme for research, technological development and demonstration under grant agreement No 314461. The European Union is not liable for any use that may be made of the information contained in this document which is merely representing the authors view.

\section{References}

[1] The European Parliament and the Council of the European Union. Directive 2010/31/EU on the energy performance of buildings. Official Journal of the European Union, L 153 (2010) 13-35.

[2] European Environment Agency. Energy and Environment Report, 2008. ISBN: 978-92-9167-980-5.

[3] European Commission Environmental Improvement Potentials of Residential Buildings (IMPRO-Building). Office for Official Publications of the European Communities, 2008. ISBN: 978-92-79-09767-6.

[4] M. Bojić, N. Nikolić, D. Nikolić, J. Skerlić, I. Miletić, A simulation appraisal of performance of different HVAC systems in an office building, Energy and Buildings 43 (2011) 1207-1215.

[5] W. Wang, J. Zhang, W. Jiang, B. Liu, Energy performance comparison of heating and air-conditioning systems for multi-family residential buildings, HVAC\&R Research 17 (3) (2011) 209-322.

[6] M. Gustafsson, J.A. Myhren, C. Bales, Comparison of two HVAC solutions: a case study, in: CLIMA 2013, Prague, Czech Republic, 2013.

[7] Z. Ma, P. Cooper, D. Daly, L. Ledo, Existing building retrofits: methodology and state-of-the-art, Energy and Buildings 55 (2012) 889-902.

[8] F. Ochs, G. Dermentzis, D. Siegele, A. Konz, W. Feist, Use of building simulation tools for renovation strategies-a renovation case study. Part of European 7th Framework Programme project iNSPiRe, 2013.

[9] MathWorks. Simulink-Simulation and Model-Based Design. 〈http://www.mathworks.se/products/simulink/〉 (accessed 25.02.14).

[10] S.A. Klein, A. Beckman, W. Mitchell, A. Duffie, TRNSYS 17-a transient systems simulation program, in: Solar Energy Laboratory, University of Wisconsin, Madison, 2011. 
[11] iNSPiRe, European Commission 7th Framework Programme project. Proposal number: 314461; Title: Development of Systematic Packages for Deep Energy Renovation of Residential and Tertiary Buildings including Envelope and Systems; Duration: 2012-10-01-2016-09-30.

[12] The Reference Framework for System Simulations of the IEA SHC Task 44/HPP Annex 38-Part B: Buildings and Space Heat Load, 2012.

[13] ISO 13370:2007-Thermal performance of buildings-Heat transfer via the ground-Calculation methods.

[14] Meteonorm. 〈http://meteonorm.com/〉 (accessed 25.02.14).

[15] Passive House Institute. EnerPHit: Certification criteria for retrofits, 2012.

[16] Passive House Institute-Passive House requirements. 〈http://www.passiv.de/en/02_informations/02_passive-houserequirements/02_passivehouse-requirements.htm $\rangle$ (accessed 25.02.14).

[17] PHPP-The Energy Balance and Passive House Planning Tool. 〈http://passiv.de/en/04_phpp/04_phpp.htm〉 (accessed 25.02.14).

[18] F. Ochs, G. Dermentzis, W. Feist, Façade integrated active components in timber-constructions for renovation-a case study, NSB, Lund, Sweden, 2014
[19] The Reference Framework for System Simulations of the IEA SHC Task 44/HPP Annex 38-Part C: Heat Pump Models-A5. Heat pump model EFKOS, 2013.

[20] Passive House Institute, Passive House Institute-Passive House Suitable Component Certificate. Compact Heat Pump System, Drexel \& Weiss Aerosmart

[21] Acticon (2008). Easy-Vent-Frisk luft i bostäder, 26-27.(in Swedish).

[22] N-Indata, NIBE-Indata till TMF:s program ver 2.1 för NIBE F750.(in Swedish).

[23] European Committee for Standardization. European Standard EN 14511-2-Air conditioners, liquid chilling packages and heat pumps with electrically driven compressors for space heating and cooling-Part 2: Test conditions, 2007.

[24] J.A. Myhren, S. Holmberg, Design considerations with ventilation-radiators: comparisons to two-panel radiators, Energy and Buildings 41 (2009) 92-100.

[25] Viessmann Vitocal Technical Guide. Vitocal 200-S Type AWB 201.B, 2011.

[26] M. Ivonen, 2007. Purmo Air Simulator Vers. 05.11.2007.

[27] Sveriges Centrum för Nollenergihus. FEBY 12-Kravspecifikation för nollenergihus, passivhus och minienergihus (in Swedish), 2012.

[28] Boverket. Swedish Building Regulations, BBR 19, BFS 2011:26 (in Swedish). ISBN 978-91-86827-41-0, 2011. 